\title{
Dimensionally Decomposed Development and Happiness
}

\author{
Muharrem Burak ÖNEMLİ
}

0000-0001-5087-6420

\section{ARTICLE INFO}

Submitted: 30. 06. 2021

Revision Requested: 14. 07. 2021

Final Revision Received: 26. 07. 2021

Accepted: 29. 07. 2021

Published Online: 15. 08. 2021

\section{Keywords:}

Economics

Happiness

Life Satisfaction

Development

Development Indicators

\begin{abstract}
A B S T RACT
The primary purpose of this study is to evaluate and compare the relative effects of different developmental dimensions on happiness. However, such an attempt requires an approach that divides the phenomenon of development into building blocks. In this respect, this study focuses on the dimensions of economic prosperity, good governance, education, health, the sustainable environment, gender equality, trade and financial flows, and mobility. Following the general trend in the literature, the relations between the country's average happiness levels calculated from microdata and the development indicators compiled from the World Bank data were analyzed using the least-squares method. In this analysis, Box-Cox transformation was used to ensure that the dependent variable, the average happiness levels, showed normal distribution. Our study reveals that all dimensions have the expected effects on happiness. However, the economic prosperity, sustainable environment, and government efficiency dimensions create the top three blocks of development that have the most significant impact on life satisfaction, respectively. On the other hand, the effects of the remaining aspects on happiness seem relatively minor. Additionally, handling the reflection of the mobility dimension on happiness deserves special treatment since the association between net migration and happiness is most likely tend to indicate a reverse causality, unlike the migration stock and life satisfaction relation.
\end{abstract}

*Corresponding Author: Muharrem Burak Önemli (Assoc. Prof.), Izmir Kâtip Çelebi University, Faculty of Economics and Administrative Sciences, Department of Economics, Izmir, Turkey $₫$ mburak.onemli@ikcu.edu.tr Citing This Article: Önemli, B. M. (2021). Dimensionally decomposed development and happiness. Sosyolojik Bağlam Dergisi, 2 (2), 1-17. Doi: $10.52108 / 2757-5942.2 .2 .1$ 
The objective of this study is to assess the relative effects of different developmental dimensions on subjective well-being. However, we need to consider an approach that divides the concept of development into building blocks. Because, in a broad sense, development or constructing economic and social progress is a multidimensional concept. Therefore, it can be considered as a union of a set of aspects and numerous dimensions that can be given in a long list, including income/wealth or economic prosperity, demography, education, health, human security, environmental and socioeconomic sustainability, gender, trade and financial flows as well as mobility and communication, work, employment and vulnerability, and good governance. This study examines the impacts of some of these dimensions of development on happiness.

In general, happiness can be taken as an indicator of utility or welfare and considered the final economic activity objective for societies. In the literature, the terms subjective well-being, happiness, and life satisfaction are often used interchangeably to refer to the same concept, although there are some differences between them. In this study, we are also following this tradition and using them in the same meaning.

A quick review of the literature on life satisfaction reveals that much of the discussion on the relationship between development and happiness at the macro level centered on the economic prosperity or income/wealth dimension. Moreover, it is almost possible to say that this relationship between the two is reduced only to the income dimension. It is natural because the widely used definitions for the development level of countries are borrowed from the World Bank classification. Accordingly, World Bank classifies countries as developed, developing, and under-developed by ranking them according to their income level. Furthermore, it is also income and wealth dimension implicitly control for the production, consumption, and capital accumulation capabilities of countries.

However, economic development is a phenomenon well above a concept that is reduced to just material aspects. On account of this, handling development in a multidimensional framework is a requirement. It is possible to say that such an approach has been obtaining the acceptance globally for a while. For instance, both development goals (the Millennium Development Goals and the Sustainable Development Goals, respectively) prepared by the United Nations have emphasized and prioritized the importance of other aspects of development.

This study attempts to examine the effect of different dimensions of development on happiness in a holistic view. Although many of those dimensions and their impacts on life satisfaction have been previously studied separately in the literature, we believe that a comprehensive approach is needed since examining different aspects does not compare their comparative effects on happiness. Moreover, studying those dimensions separately may also potentially introduce biased estimates due to omitted relevant variable problems. For instance, considering the development and happiness relationship by confining them to income ignores health and education dimensions. This will produce a higher estimate of the income coefficient than an approach involving health and education dimensions. This is the central idea motivating this line of research. The remainder of this paper is organized as follows; an overview of the developmental dimensions and happiness relation is outlined in section 2 , and section 3 provides the data and econometric model. The results are discussed in section 4, and section 5 summarizes the key findings and concludes.

\section{An Overview for the Developmental Dimensions and Happiness Relation}

Let us start with happiness, but first, thanks to (Inglehart, et al., 2014), a significant number of scholars and survey researchers put their efforts into the World Values Surveys (WVS). Their precious work allows researchers from different disciplines to study the numerous issues related to 
happiness, subjective well-being, norms, and cultural differences worldwide. The WVS consists of nationally representative surveys that have been repeatedly given in six waves since 1981 and conducted in nearly 100 countries that contain almost 90 percent of the world's population.1 WVS collects individual-level information on various variables, including the opinions of individuals on politics, economy, religion, social and ethical issues, social relationships, and happiness and life satisfaction using a standard questionnaire. The following question of the WVS: "Taking all things together, would you say you are: (1) very happy, (2) quite happy, (3) not very happy, or (4) not at all happy" constitutes our primary variables of happiness. However, for ease of interpretation, we rearranged the encoded answers in our analysis from (1) not happy at all to (4) very happy.

Figure 1 presents the distribution of average happiness scores over geography for the last four waves of WVS. From the provided maps, the geographic clusters in mean happiness are clear; therefore, this phenomenon needs to be addressed in studying the average happiness across countries. ${ }^{2}$ According to average happiness scores, low-income countries are stacked into the lower tail of the distribution of mean happiness as expected. However, relatively high-income countries constitute the upper tail of the distribution with few exceptions, such as Viet Nam, Tanzania, and Nigeria.

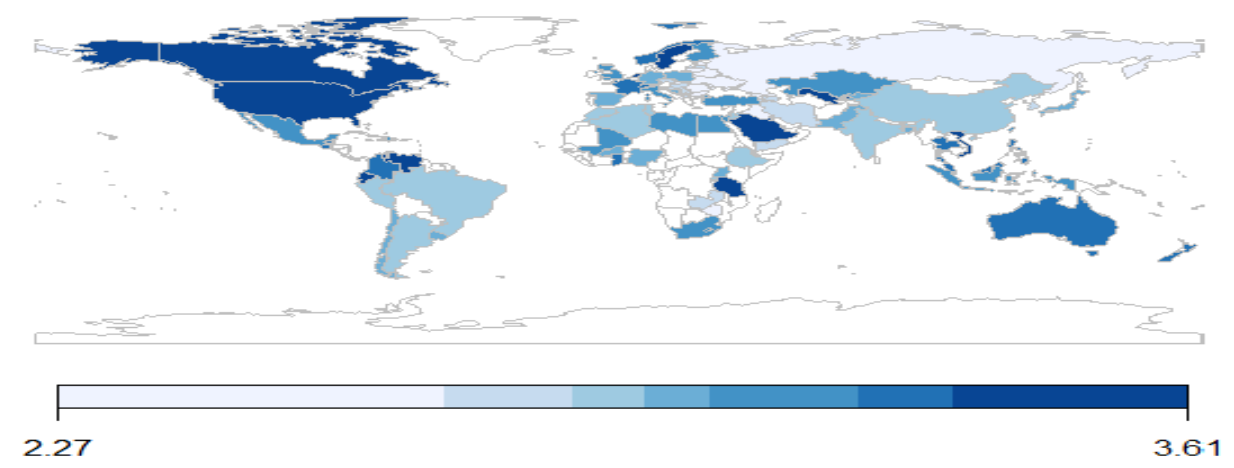

Figure 1: Geographical Distribution of Mean Happiness Scores across Countries for the 1981-2014 Period

When it comes to development, the UNDP's human development index (HDI), which unifies health, education and welfare dimensions of development, is one very popular indicator recently. UNDP categorizes the countries as low, medium, high, and very highly developed countries based on the certain thresholds of index values. Figure 2 presents the correlation between HDI and mean

\footnotetext{
${ }^{1}$ In six waves, namely, 1981-1984, 1990-1994, 1995-1998, 1999-2004,2005-2009, and 2010-2014, the total of 341,271 individuals have been surveyed in 99 countries. The surveyed countries are: Albania, Algeria, Andorra, Argentina, Armenia, Australia, Azerbaijan, Bahrein, Bangladesh, Belarus, Bosnia, Brazil, Bulgaria, Burkina Faso, Canada, Chile, China, Colombia, Croatia, Cyprus, Czechia, Dominican Republic, Ecuador, Egypt, El Salvador, Estonia, Ethiopia, Finland, France, Georgia, Germany, Ghana, Guatemala, Hong Kong, Hungary, India, Indonesia, Iran, Iraq, Israel, Italy, Japan, Jordan, Kazakhstan, Kuwait, Kyrgyzstan, Latvia, Lebanon, Libya, Lithuania, Macedonia, Malaysia, Mali, Mexico, Moldova, Montenegro, Morocco, Netherlands, New Zealand, Nigeria, Norway, Pakistan, Palestine, Peru, Philippines, Poland, Puerto Rico, Qatar, Romania, Russia, Rwanda, Saudi Arabia, Serbia, Singapore, Slovakia, Slovenia, Slovenia, South Africa, South Korea, Spain, Sweden, Switzerland, Taiwan, Tanzania, Thailand, Trinidad, Tunisia, Turkey, Uganda, Ukraine, United Kingdom, United States, Uruguay, Uzbekistan, Venezuela, Viet Nam, Yemen, Zambia, and, Zimbabwe.

2 Since the average national happiness scores of countries show geographic clusters for all from the least developed to the richest, we can assert that spatial relations are necessary for analyzing the relationship between economic variables and average levels of happiness at macro-level. However, the best of our knowledge, (Stanca, 2010) is the only study taking into account the spatial distribution of happiness.
} 
happiness scores for the group of high and very highly developed countries compared to the middle and lower developmental groups.

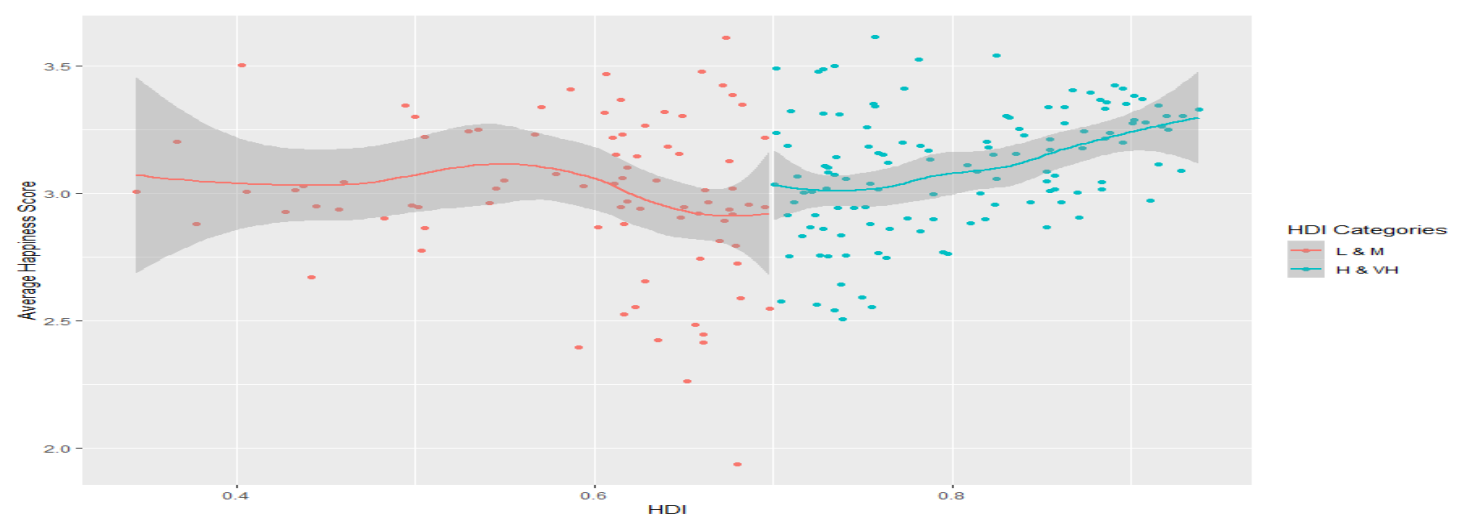

Figure 2: HDI and Average Happiness Score for Relatively Low and High Developed Countries

As seen from the figure, the average happiness tends to oscillate horizontally around the category happy (average score 3) for relatively low developed countries. On the other hand, the average happiness score seems to rise as HDI increases for the highly developed group. Another observation that we can make is that the variability of happiness score of the relatively lower developed group is more substantial than their wealthier counterparts. The different patterns in the mean happiness and HDI relation for the relatively developed and the lower developed groups would seem somehow related to this second observation. Accordingly, the countries with higher HDI tend to exhibit a more homogeneous distribution in aspects of development than the lower developed countries since their performance on the dimensions, which put them into the higherdeveloped group, is closer to the ideal reference points in the higher-developed group those features. However, the situation is reversed for the relatively lower developed group because there are more ways and possibilities to deviate from the ideal reference points compared to approaching them. Therefore, it is natural to exhibit more variability in the utility outcome of the lowerdeveloped group depending on the variety of those deviations.

Studying the different elements and dimensions of development may be a very tiring task due to the abundance of indicators and aspects of economic and social progress. Therefore, a more concise roadmap is required for variable selection. In this respect, we will first focus on the dimensions prioritized by the United Nations Development Program. The UNDP data portal shares the development data of countries by segregating its aspects with the related variables. ${ }^{3}$ This study will focus on the dimensions of economic prosperity, good governance, education, health, sustainable environment, gender equality, trade and financial flows, and mobility.

The relation between economic prosperity on happiness is extensively studied in subjective wellbeing literature and has been the center of the debate for many years. Although the higher income implies more happiness on average within a given country, Easterlin's (1974) seminal study contends that the average level of reported happiness does not accompany the increases in per capita national income in a cross-country comparison the economically developed countries. Known as the Easterlin paradox, it takes its roots from the theories of relative preference and adaptive expectations. According to (Duesenberry, 1949), individual's utility for income is interdependent on that of other people called the reference group and the adaptive expectations, which implies the obtained previous income levels. As stated by Hagerty and Veenhoven (2003), raising the income through economic growth may potentially lead to no additional utility since such

\footnotetext{
3 See http://hdr.undp.org/en/data
} 
an alteration in prosperity will not create a relative change compared to others. Secondly, individuals' expectations will adjust over time to the increased income.

The absolute utility theories assume that larger incomes increase happiness by enabling individuals to satisfy the more significant part of their needs. Thus, these theories foresee subjective well-being as an increasing function of income. ${ }^{4,5}$ Another issue for economic prosperity and life satisfaction intercourse is the shape of their relationship. The positive correlation between economic progress and happiness is concave in the national income per capita. Therefore, such arguments are not surprising for economists who are familiar with the notions of decreasing marginal utility and risk aversion.

Government and Happiness: The subjective well-being literature also recognizes the role of government. The studies of (Bjørnskov, Dreher, \& Fischer, 2007),(Ram, 2009),(Perovic \& Golem, 2010), and (Yamamura, 2011) focus on the government size and life satisfaction relation. This line of research mostly centers on degradation or enhancement in overall happiness based on whether or not the government size, measured by government expenditure, is higher than the optimal level. Accordingly, it is possible to say that this research avenue takes the government quite narrowly and confines its role solely on affecting the economy via its expenditures.

However, government activities directly influence the economy with a wide range of features from the quality in the provision of public services to the credibility of governmental actions. Consistently, there is another line of research focusing on governance quality. For example, (Helliwell \& Huang, 2008) finds a close relationship between government quality and subjective well-being. The authors calculate the government quality as the average of governmental effectiveness, regulatory quality, the rule of law, and control of corruption. Similarly, (0tt, 2010) suggests that the correlation between technically good governance and happiness seems to be independent of cultural differences, i.e., their relation is valid for all world regions. Furthermore, (Ott J. C., 2011) contends that good governance brings about a higher level of happiness and decreases inequality of life satisfaction within a country.

Social Opportunities (Education and Health): According to (Sen, 2000), education and health, which represent social opportunities, facilitate economic participation.6,7 These opportunities affect the individual's substantive freedom for a better life. Moreover, social opportunities in development should be taken as a multidimensional concept with a series of dynamic reflections. For example, (Sen, 2000) states that creating social opportunities contributes to economic development and significant reductions in mortality rates. Lower mortality rates, in turn, assist in reducing birth rates, stiffening the influence of basic education-especially female literacy and schooling- on fertility behavior.

We can also see this multi-dimensionality and the dynamic pattern in the components of social opportunities separately. For example, education, the fundamental element of absorbing modern technology and increasing productive capacity for sustainable growth, has become widespread and accessible even in developing countries as never seen before in history. Similarly, the factors such as the provision of public health care, the availability of increased nutrition options and better shelter opportunities, etc., have led to an increase in the chances of reaching advanced ages by reducing the mortality rate. These developments result in a drastic rise in life expectancy in some

\footnotetext{
4 (Clark \& Senik, 2010) provides a comprehensive review of the relationship between income and happiness. 5 Studies of (Hagerty \& Veenhoven, 2003), (Clark, Frijters, \& Shields, 2008), (Layard, Mayraz, \& Nickell, 2010), (Deaton, 2008), (Stevenson \& Wolfers, 2008), (Inglehart, Fao, Peterson, \& C, 2008), and (Blanchflower, 2008)are only a few of an extensive literature, which focus on the within-country cross-section and crosssection of countries and showing the positive relation between the change in real income - happiness.

${ }^{6}$ Indeed (Sen, 2000) acknowledges the development of a free press as another important component of social opportunities. Unfortunately, we do not have data to control this dimension.

7 Education and health together also called the human capital dimension of development.
} 
parts of the world. In the rest of the world, a slower rise is observed over the last two centuries. There is no doubt that these improvements have directly affected the welfare of people around the world.

Finally, another critical aspect for the welfare effects of these two dimensions is their substantial relationship with the concept of public goods, which refer to the economic areas that the market mechanism is not sufficient for achieving efficiency. Accordingly, for example (Sen, 2000, p.118119) makes the following observations regarding the welfare effects of social opportunities:

\begin{abstract}
"In fact, however, some of the most important contributors to human capability may be hard to sell exclusively to one person at a time. This is especially so when we consider the socalled public goods, which people consume together rather than separately... I may be willing to pay my share in a social program of malaria eradication, but I cannot buy my part of that protection in the form of private good (like an apple or a shirt). It is a public good malaria-free surroundings-which we have to consume together... Defense, policing and environmental protection are some of the fields in which this kind of reasoning applies. There are also rather mixed cases. For example, given the shared communal benefits of basic education, which may transcend gains of the person being educated, basic education may have a public good component as well (and can be seen as a semipublic good). The persons receiving education do, of course, benefit from it, but in addition a general expansion of education and literacy in a region can facilitate social change (even the reduction of the fertility and mortality) and also help to enhance economic progress from which others too benefit."
\end{abstract}

Environmental Issues: Environmental sustainability, which should also be taken within the perspective of public good, is another dimension that has direct linkages to the welfare of societies. There is no doubt environmental degradation along with its negative externalities is one of the most fundamental and alarming problems of our time. Its existence, in general, has not only been reducing our well-being by threatening our health but also is endangering the future of humankind by putting our planet at stake. The effect of environmental problems on happiness has drawn the attention of researchers to the topic due to both the importance of the issue and their close linkages between them. For example, (Welsch, 2002) focuses on the trade-off between prosperity and the environment and finds that impact of air pollution on happiness exerts substantial monetary valuation to improve air quality. (Welsch, 2009) discusses the potential of happiness research in reaching the socially optimal environmental quality. Additionally, (Carbonell \& Gowdy, 2007) find negative effects for concerns regarding ozone pollution on subjective well-being. Similarly, Cuñado \& Gracia, 2013 showed that climate and pollution indicators significantly affect observed regional differences even those socioeconomic variables.

In terms of gender equality, the utilitarian approach in economics became a subject of a series of points of criticism, mostly coming from development economists. For example, (Sen, 2000, p. 6263) writes: "The utility calculus can be deeply unfair to those who are persistently deprived; for example, the usual underdogs in stratified societies,..., hopelessly subdued housewives in severely sexist cultures. "These critiques have found some support and reflections; as a result, international organizations began to focus more on the distribution of utility, besides its maximization. For example, promoting gender equality and empowering women was an essential component of the United Nation's Millennium Development Goals and prioritized current Sustainable Development Goals.

In parallel to this, many reports of international organizations such as ILO, IMF, and World Bank highlight the importance of this concept. ${ }^{8}$ Furthermore, it is possible to observe that the primary approach of most of these organizations frequently centered on the frameworks of the women's

8 See, for example, (ILO, 2010), (IMF, 2013), and, (World Bank, 2011). 
participation in the formal economy, their skill utilization, ability, and attributes of labor affecting their productive capacity as well as their earning potential. For example, (World Bank, 2011) takes gender equality in development in a much broader sense. Accordingly, gender equality can enhance economic efficiency and improve other development outcomes in three ways: (i) removing barriers for women in areas including education, economic opportunities, and productive inputs can generate broad productivity gains; (ii) improving women's status feeds many other development outcomes, including those for their children; (iii) enabling women to equal chances with men in social life, politics and decision making processes lead over time to more representative, and more inclusive, institutions and policy choices and thus to a better development path.

Economic Liberalization and Trade: Economic liberalization and financial flows are thought to be other relevant factors, which reflect the macroeconomic climate of development. Most of the literature concentrates on the growth creation potential of this dimension; and, the moot point mostly takes place around whether a more intensive trade liberalization supports development by accelerating or boosting the economic growth. Therefore, it is possible to link the effect of economic liberalization on happiness with its impact on growth. However, we believe another channel is more important in the axis of trade and happiness. Accordingly, in the economic liberalization and happiness relationship, the sectoral effects of the trade on employment would constitute a more appropriate structural framework.

International Migration: According to the World Bank, with over 200 million international and over 700 million internal migrants, migration is likely to remain a critical issue for development. ${ }^{9}$ Besides the advances such as lower costs in communication and transportation and growing opportunities for accessing information, the factors having direct linkages to development, including changes in demography and climate, income disparities, etc., would seem to stimulate the impetus to migration in the near future. According to (Sjaastad, 1962), migration decisions are made based on the comparison of monetary and non-monetary returns and costs. ${ }^{10}$ However, depending on the realized migration decisions, social costs and benefits also arise because migration would involve costs and benefits to not only migrants but also non-migrants.

The migration literature within development economics is mainly centered on internal migration. However, the increasing number of international migrants, mainly from relatively less developed countries to developed ones, has begun to draw the attention of researchers to the global movements. ${ }^{11}$ Numerous factors affect international migration. Factors such as income differentials in the source and destination countries, income inequality, lack of opportunities in the source countries, macroeconomic conditions, demographic structure, political climate and freedoms, immigration laws, distance between the source and destination countries, monetary cost of immigration, cultural and language differences etc., all influence the intensity of international migration.

The association between migration and happiness (Polgreen \& Simpson, 2011) examines how the average score of happiness affects the global movements across borders. Accordingly, they relate happiness to emigration rate, immigration rate, net immigration rate, respectively, and find the Ushaped relation for each of them. Moreover, the authors also recognize the possibility of reverse causality, i.e., migration could influence happiness by making people more or less happy in the destination countries due to the presence of immigrants. However, the authors do not show an

\footnotetext{
9 See (Coordinated by UNFPA \& IOM, 2013).

10 The study by Sjaastad (1962) examines the topic within internal migration framework. Later, Polgreen and Simpson (2011) put Sjaastad's main idea in the international migration framework. According to this interpretation, if the utility of living abroad exceeds that of staying home net of migration costs (which could include distance, language, people left behind home, etc.), the individual would move abroad.

11 See, for example, (Massey, 1988), (Borjas, 1989), (Massey, et al., 1993), and (Clark, Hatton, \& Williamson, 2007).
} 
attempt to control it. In the present work, we will explore the linkage between net migration to happiness by estimating the average happiness level as a function of net migration.

\section{Data and Econometric Models}

We acquire data on happiness from the World Values Surveys (WVS). Using all six waves of the WVS, we calculated the average happiness score by the country for each available year. Those happiness scores were used as the dependent variable's values in the econometric estimations. Moreover, concerning development, we attempt to evaluate the impact of each dimension given in Table 1 on happiness. ${ }^{12}$ Table 1 also provides selected indicators and the corresponding dimension, and some additional control variables for demographics and macroeconomic conditions.

Table 1: Independent Variables and Their Selection Motivations

\begin{tabular}{|c|c|}
\hline Variables & Controls \\
\hline : GDP per capita, PPP & Economic prosperity dimension \\
\hline GovEff $\quad$ : Government effectiveness indicator & Good governance dimension \\
\hline EducExpd: Education expenditure & Education dimension \\
\hline LifeExpc : Life expectancy at birth & Health dimension \\
\hline : Carbon-dioxide emissions in mt per capita & Sustainable environment dimension \\
\hline : Female-to-male ratio in employment & Gender equality dimension \\
\hline :Trade openness & Trade and financial flows dimension \\
\hline $\begin{array}{cl}\text { MgrtnR } & \begin{array}{l}\text { Percentages of net migration and migration } \\
\text { stock in population }\end{array}\end{array}$ & Mobility dimension \\
\hline $\begin{array}{ll}\text { Inf } & \text { : Inflation Rate } \\
\text { Unemp } & : \text { Unemployment Rate }\end{array}$ & Macroeconomic conditions \\
\hline $\begin{array}{ll}\text { Pop } & \text { : Population } \\
\text { BirthR } & \text { : Crude birth rate per } 1000 \text { people }\end{array}$ & Demographics \\
\hline
\end{tabular}

Except for the government effectiveness indicator to control the governance dimension and the female-to-male ratio to evaluate the impact of the gender dimension, we retrieve other independent variables from the World Development Indicators (WDI) provided by the World Bank. The selected indicator for assessing the influence of economic prosperity on happiness is GDP per capita purchasing power parity (PPP), to be able to control for price differentials between countries. Other independent variables obtained from WDI and their corresponding dimensions are as follows: education expenditure, measured by the share of government expenditure on education in GDP, examines the impact of the education dimension; life expectancy at birth is used to attempt to test the health dimension; carbon dioxide emissions in metric tons per capita to audit sustainable environment dimension; trade openness, which is the share of summation of exports and imports in GDP, is included to capture the impact of trade and financial flows; and finally percentages of net migration and migration stock in the population are to embodied in accounting for the mobility dimension of development. Apart from those, inflation and unemployment rates comprehend to control for the impact of macroeconomic conditions. In contrast, population and crude birth rate per 1000 people are added to measure the effect of demographic factors on happiness.

12 Due to the data availability, we cannot control all dimensions given in the UNDP data portal at this point. Therefore, the aspects that we can control here selected in a way that not to create the loss in degrees of freedom in the regression analysis. Additionally, good governance is not an explicitly stated dimension in the UNDP data portal. However, since it is a part of Sustainable Development Goals, and moreover, considering previous studies found that government has the potential to create an impact on happiness with its actions, this dimension included as an independent variable. Likewise, we have added the inflation and unemployment rates, taking into account the effects of macroeconomic conditions in order to avoid the results of a possible omitted relevant variable bias in the econometric analysis. 
On the other hand, the government effectiveness indicator is obtained from the Worldwide Governance Indicators (WGI) of the World Bank. ${ }^{13}$ The World Bank defines this indicator as: "Government Effectiveness captures perceptions of the quality of public services, the quality of the civil service and the degree of its independence from political pressures, the quality of policy formulation and implementation, and the credibility of the government's commitment to such policies. Estimate gives the country's score on the aggregate indicator, in units of standard normal distribution, i.e., ranging from approximately -2.5 to 2.5." Finally, we retrieve the female-to-male ratio in employment from the Employment Statistics of the International Labor Organization (ILO).

We use the averages of the last four years of the values of independent variables before the survey year for most independent variables to smooth the effect of business cycles and mitigate the influences of possible extreme conditions on corresponding variables. On the other hand, due to the data availability, we employ the most current values before the survey year for government effectiveness, the female-to-male ratio in employment, and the migration-related covariates. However, given that these variables show a very stable movement over time for countries, this does not make much difference. Table 2 includes the summary statistics for each variable in our data set.

Table 2: Descriptive Statistics

\begin{tabular}{|l|c|c|c|c|c|c|}
\hline Variables & Min & $\begin{array}{c}\text { 1st } \\
\text { Quartile }\end{array}$ & Median & Mean & $\begin{array}{c}\text { 3rd } \\
\text { Quartile }\end{array}$ & Max \\
\hline Happiness & 1.94 & 2.91 & 3.05 & 3.06 & 3.26 & 3.61 \\
\hline GDP per capita, PPP & 701.4 & 6142.0 & 11981.6 & 17268.9 & 24590.0 & 118551.2 \\
\hline Government Efficiency index & -1.72 & -0.44 & 0.09 & 0.29 & 1.05 & 2.17 \\
\hline Education Spending in GDP & 1.07 & 3.22 & 4.37 & 4.33 & 5.28 & 9.90 \\
\hline Life Expectancy & 45.85 & 68.30 & 72.21 & 70.96 & 76.08 & 83.16 \\
\hline Co2 & 0.06 & 1.65 & 4.39 & 5.98 & 8.12 & 51.55 \\
\hline $\begin{array}{l}\text { Female to male ratio in } \\
\text { employment }\end{array}$ & 9.00 & 57.02 & 71.22 & 65.65 & 79.36 & 98.57 \\
\hline Trade Oppenness & 13.51 & 40.83 & 59.58 & 71.45 & 87.86 & 401.40 \\
\hline $\begin{array}{l}\text { Percentage of net migration } \\
\text { in population }\end{array}$ & -7.93 & -0.92 & -0.19 & 0.38 & 0.83 & 55.72 \\
\hline $\begin{array}{l}\text { Percentage of migration } \\
\text { stock in population }\end{array}$ & 0.03 & 0.79 & 3.10 & 7.70 & 9.87 & 82.49 \\
\hline Inflation & -1.90 & 2.93 & 6.24 & 55.77 & 13.85 & 2000.95 \\
\hline Unemployment & 0.50 & 4.47 & 7.13 & 8.79 & 10.40 & 36.01 \\
\hline Population in thousands & 71.7 & 6,689 & 25,150 & 90,190 & 67,380 & $1,334,000$ \\
\hline Birth Rate in 1000 people & 7.10 & 11.79 & 16.10 & 19.22 & 24.75 & 49.22 \\
\hline
\end{tabular}

The econometric models that are estimated are expressed as follows:

$$
\begin{aligned}
\text { Happiness }= & \beta_{0}+\beta_{1} \log \left(G D P_{p e}\right)+\beta_{2} \text { GovEff }+\beta_{2} \text { EducExpd }+\beta_{4} \text { LifeExpe }+ \\
& \beta_{5} \log \left(C_{2} 2_{p e}\right)+\beta_{6} \text { FMR }+\beta_{7} \text { TO }+\beta_{8} \text { MgratnR }+ \\
& \gamma_{1} \operatorname{lnf}+\gamma_{2} \text { Unemp }+\gamma_{3} \log (\text { Pop })+\gamma_{4} \log (\text { BirthR })+\varepsilon ;
\end{aligned}
$$

and,

$$
\begin{gathered}
\text { Happiness }=\beta_{0}+\beta_{1} \log \left(G D P_{p e}\right)+\beta_{2} \text { Gov Eff }+\beta_{a} \text { EducExpd }+\beta_{4} \text { LifeExpc }+ \\
\beta_{5} \log \left(\mathrm{CO}_{\mathrm{pe}}\right)+\beta_{6} \text { FMR }+\beta_{7} \text { TO }+\beta_{9} M \text { grtn } R+\beta_{9} M_{g r t n R^{2}}+
\end{gathered}
$$

${ }^{13}$ Detailed documentation of the WGI is available at www.govindicators.org. Please see also (Kaufmann, Kraay, \& Mastruzzi, 2010) for more detailed information on the WGI. 


$$
\gamma_{1} \operatorname{lnf}+\gamma_{2} \text { Unemp }+\gamma_{2} \log (\text { Pop })+\gamma_{4} \log (\text { BirthR })+\varepsilon_{\text {. }}
$$

where $\beta_{j}$ 's for $j=1, \ldots, 9$ represent the model's parameters to be estimated for different developmental dimensions while $\gamma_{i}$ 's for $i=1_{, \ldots,}$, denote the parameters to be estimated for the macroeconomic conditions and demographics. Finally, $\beta_{0}$ and $\varepsilon$ represent the intercept coefficient and the error term of the model, respectively.

We evaluate the impact of dimensions of development on happiness by using two sets of econometric models. These two econometric models differ only in the square of the immigration rate added to the former for the latter to control the effect of a possible non-linearity in the mobility-happiness relationship. Additionally, we use two variables for the mobility dimension: the percentage of net migration in the population and the ratio of migration stock to the population. Hence, we estimate two models in Equation (1) and (2) for both migration controls. ${ }^{14}$

However, diagnostic tests detect that the assumptions of the linear model did not seem to be met. This situation is not particularly surprising since, as shown in the summary statistics, most of the data of happiness scores are clustered in the upper tail of its distribution, making the distribution of happiness skewed to the left.

(Box \& Cox, 1964) proposed power of transformations that can be used with non-negative responses. The procedure finds the appropriate power transformation by using likelihood functions to transform non-normal dependent variables into the symmetric shape. In this respect, we implemented the Box-Cox transformation in our regressions and found the optimal transformation value as being approximately $2 .{ }^{15}$ Therefore, we transformed the dependent variable as follows and substitute the modified values into Equations 1 and 2.

$$
\text { Happiness }^{\text {(I) }}=\frac{\text { Happiness }^{2}-1}{2}
$$

Please note that luckily the Box-Cox transformation will not create any change in the interpretations of the estimated regression coefficients since it transforms happiness scores in one direction only by preserving the order of the values of happiness. Furthermore, the original happiness scores were assigned to give an order for the different levels of happiness with no cardinal meaning. Therefore, the Box-Cox transformation will keep the exact ordering, just with other scores. In microeconomy, this refers to the monotonic change in a utility's function. Additionally, the Box-Cox transformation allows us to use the OLS method as a reliable estimation method since, after the employment of this procedure, all linear model assumptions seem satisfied. ${ }^{16}$

\footnotetext{
14 We are estimating four models where each labeled as one from Model 1 to Model 4. Specifically, Model 1 and Model 2 estimate both of the Equations 1 and 2 for the percentage of net migration in population. Model 3 and Model 4 are their counterparts which include the proportion of migration stock in population (and its square in the latter) as the independent variable(s), respectively. Please note that Model 1 and Model 2 are the main models we want to focus. However, we estimate Model 3 and Model 4 as the complementary regressions with an objective for clarifying the interpretations of the net migration-happiness relationship.

15 In search of the Box-Cox transformation power $(\lambda)$, we used the range $(-5,5)$. The optimal values of $\lambda$ which maximize the likelihood function are found to be equal to 2.17 for the Models 1 and 4, 2.07 for the Model 2, and 1.97 for the Model 3.

16 We used the R's gvlma package prepared by Pena and Slate (2019) for diagnostic tests for whether the assumptions of the linear model are met for our four models. This package provides a tool to perform a single global test and specific directional tests designed to detect skewness, kurtosis, a nonlinear link function, and heteroscedasticity to assess the linear model assumptions. The results of the diagnostic tests are provided in Table 3. As shown in Table 3, all four models satisfy all of the linear model assumptions. Therefore, the linear model is a befitting and suitable procedure for the models at hand.
} 


\section{$4 \quad$ Results}

The OLS regressions are estimated for four models by using transformed happiness score, given in Equation (3), as the dependent variable. Most of the variables have expected impacts on transformed happiness. The regression results appear in Table 3.

The results reveal a positive and statistically significant relationship between per capita GDP and the transformed value of happiness in all four specifications. The estimated coefficients range from 0.49 to 0.53 . Generally speaking, our estimates suggest that the higher income implies more happiness on average. In this respect, our results seem to support the utility theories compared to relative preference and adaptive expectations. Furthermore, by using the logarithm of GDP per capita PPP, we emphasize the diminishing marginal utility of income. That is to say, an increase of GDP per capita PPP by some amount in a relatively lower-income country has a more significant effect on the standard of living than the equivalent monetary increase in a relatively wealthier country.

Government efficiency seems to be another significant dimension based on results. Specifically, according to our estimates, one standard deviation increase in the government effectiveness index changes the estimated transformed happiness by varying from 0.143 (in Model 2) to 0.86 (in Model 4) points, ceteris paribus. This result points out the need to view the government as an essential actor with direct effects on average happiness, even without paying attention to specific policies or their influence on particular groups at macro or individual levels. Such is an intriguing result because people see governments contribute less to happiness than any other potential source (Headeym \& Wearing, 1992). However, our results suggest that government efficiency is the third important factor after per capita income and a sustainable environment.

Furthermore, (Headeym \& Wearing, 1992) also state that governments cannot directly influence people's well-being. Still, they are the source of providing facilities and opportunities for a higher level of happiness in different life domains, including leisure, work, and even family life. Hence, the government's indirect effect is more pronounced on people's lives. Then, a natural question to ask is how we can explain the mismatch between the people's assessments regarding the role of the government on their subjective well-being and the accentuated effect of government on the average happiness scores. A possible explanation for this would be the quality and prevalence of governmental features related to many factors, such as economic power, the rule of law, legal framework, and guarantees for exclusive rights, to create a conventional and constant environment for the people of a country. For this reason, most people are likely to underestimate the importance and primary role of these factors on their happiness, which might tend to reflect itself withincountry micro studies. On the other hand, a comparison of cross-sections of countries deploys the impact of government efficiency on happiness by showing its importance more clearly.

Table 3: OLS Regression Results

\begin{tabular}{|l|c|c|c|c|}
\hline Explanatory Variables & Model 1 & Model 2 & Model 3 & Model 4 \\
\hline log GDP per capita, PPP & $0.495^{* * *}$ & $0.488^{* * *}$ & $0.530^{* * *}$ & $0.513^{* * *}$ \\
& $(0.125)$ & $(0.127)$ & $(0.124)$ & $(0.123)$ \\
\hline Government efficiency & $0.148^{*}$ & $0.143^{*}$ & $0.160^{*}$ & $0.186^{*}$ \\
& $(0.079)$ & $(0.081)$ & $(0.077)$ & $(0.077)$ \\
\hline Education spending share in GDP & $0.082^{* *}$ & $0.080^{* *}$ & $0.077^{* *}$ & $0.087^{* * *}$ \\
& $(0.032)$ & $(0.032)$ & $(0.0315)$ & $(0.0314)$ \\
\hline Life Expectancy & $0.029^{* *}$ & $0.029^{* *}$ & $0.022^{*}$ & $0.025^{* *}$ \\
& $(0.013)$ & $(0.0127)$ & $(0.013)$ & $(0.013)$ \\
\hline log Co2 emission & $-0.242^{*}$ & $-0.244^{*}$ & -0.159 & -0.148 \\
& $(0.132)$ & $(0.132)$ & $(0.133)$ & $(0.131)$ \\
\hline Female to male ratio in & $0.009^{* * *}$ & $0.0087^{* * *}$ & $0.007^{* *}$ & $0.008^{* * *}$ \\
employment & $(0.003)$ & $(0.003)$ & $(0.003)$ & $(0.0029)$ \\
\hline
\end{tabular}




\begin{tabular}{|c|c|c|c|c|}
\hline Trade openness & $\begin{array}{c}0.0006 \\
(0.0008)\end{array}$ & $\begin{array}{c}0.0006 \\
(0.0009)\end{array}$ & $\begin{array}{l}0.0005 \\
(0.0009)\end{array}$ & $\begin{array}{c}0.0008 \\
(0.0009)\end{array}$ \\
\hline $\begin{array}{l}\text { Percentage of net migration in } \\
\text { population }\end{array}$ & $\begin{array}{l}0.027^{* * *} \\
(0.009)\end{array}$ & $\begin{array}{l}0.035^{*} \\
(0.020)\end{array}$ & - & - \\
\hline $\begin{array}{l}\text { Square of percentage of net } \\
\text { migration in population }\end{array}$ & - & $\begin{array}{l}-0.0002 \\
(0.0004)\end{array}$ & - & - \\
\hline $\begin{array}{l}\text { Percentage of migration stock in } \\
\text { population }\end{array}$ & - & - & $\begin{array}{l}-0.0001 \\
(0.006)\end{array}$ & $\begin{array}{l}-0.017^{*} \\
(0.010)\end{array}$ \\
\hline $\begin{array}{l}\text { Square of percentage of } \\
\text { migration stock in population }\end{array}$ & - & - & & $\begin{array}{l}0.0003^{* *} \\
(0.0001)\end{array}$ \\
\hline Inflation & $\begin{array}{l}-0.0003 \\
(0.0002)\end{array}$ & $\begin{array}{l}-0.0003 \\
(0.0002)\end{array}$ & $\begin{array}{l}-0.0004^{*} \\
(0.0002)\end{array}$ & $\begin{array}{l}-0.0003 \\
(0.0002)\end{array}$ \\
\hline Unemployment & $\begin{array}{l}-0.0073 \\
(0.008)\end{array}$ & $\begin{array}{l}-0.0074 \\
(0.0089)\end{array}$ & $\begin{array}{l}-0.0015^{*} \\
(0.008)\end{array}$ & $\begin{array}{c}-0.0014^{*} \\
(0.008)\end{array}$ \\
\hline log Population & $\begin{array}{l}0.150^{* * *} \\
(0.035)\end{array}$ & $\begin{array}{l}0.145^{* * *} \\
(0.036)\end{array}$ & $\begin{array}{l}0.132^{* * *} \\
(0.035)\end{array}$ & $\begin{array}{l}0.131^{* * *} \\
(0.035)\end{array}$ \\
\hline log Birth rate & $\begin{array}{l}0.157^{* * *} \\
(0.200)\end{array}$ & $\begin{array}{l}0.147^{* * *} \\
(0.187)\end{array}$ & $\begin{array}{l}0.147^{* * *} \\
(0.189)\end{array}$ & $\begin{array}{l}0149 * * * \\
(0.187)\end{array}$ \\
\hline Intercept & $\begin{array}{c}-10.080^{* * *} \\
(1.697) \\
\end{array}$ & $\begin{array}{l}-9.506^{* * *} \\
(1.687)\end{array}$ & $\begin{array}{c}-9.172^{* * *} \\
(1.634) \\
\end{array}$ & $\begin{array}{c}-9.277^{* * *} \\
(1.634) \\
\end{array}$ \\
\hline $\begin{array}{l}\text { Test for Heteroskedasticity } \\
\text { (p-value) }\end{array}$ & $\begin{array}{c}1.75 \\
(0.186)\end{array}$ & $\begin{array}{c}1.676 \\
(0.195)\end{array}$ & $\begin{array}{c}1.069 \\
(0.301)\end{array}$ & $\begin{array}{c}1.542 \\
(0.504)\end{array}$ \\
\hline $\begin{array}{l}\text { Test for Skewness } \\
\text { (p-value) }\end{array}$ & $\begin{array}{c}0.031 \\
(0.860)\end{array}$ & $\begin{array}{c}0.107 \\
(0.744)\end{array}$ & $\begin{array}{c}0.022 \\
(0.882)\end{array}$ & $\begin{array}{c}0.111 \\
(0.739)\end{array}$ \\
\hline $\begin{array}{l}\text { Test for Kurtosis } \\
\text { (p-value) }\end{array}$ & $\begin{array}{c}2.845 \\
(0.092)\end{array}$ & $\begin{array}{c}2.729 \\
(0.099)\end{array}$ & $\begin{array}{l}1.500 \\
(0.221)\end{array}$ & $\begin{array}{c}1.421 \\
(0233)\end{array}$ \\
\hline $\begin{array}{l}\text { Test for Link Function } \\
\text { (p-value) }\end{array}$ & $\begin{array}{c}0.194 \\
(0.660)\end{array}$ & $\begin{array}{c}0.109 \\
(0.742)\end{array}$ & $\begin{array}{c}0.195 \\
(0.659)\end{array}$ & $\begin{array}{c}0.259 \\
(0.611)\end{array}$ \\
\hline $\begin{array}{l}\text { Global Stat } \\
\text { (p-value) }\end{array}$ & $\begin{array}{c}4.819 \\
(0.306)\end{array}$ & $\begin{array}{c}4.621 \\
(0.329)\end{array}$ & $\begin{array}{c}2.786 \\
(0.594)\end{array}$ & $\begin{array}{c}3.333 \\
(0.504)\end{array}$ \\
\hline R-square & 0.620 & 0.621 & 0.590 & 0.601 \\
\hline Number of observations & 151 & 151 & 160 & 160 \\
\hline
\end{tabular}

Notes: The numbers in the parentheses for the estimates of the coefficients are standard errors. Furthermore, "***", "**" and "*" represent $1 \%, 5 \%$ and $10 \%$ significance levels, respectively. Finally, the numbers in the parentheses are p-values for linear model diagnosis tests.

Health and education dimensions also seem to create positive and significant effects on the utility in all models. These are the expected effects since education and health are acknowledged as social opportunities. Accordingly, the results support that a higher level of happiness is associated with higher social opportunities in general. This finding is not a surprising outcome given the roles of these two dimensions as a public good and their potential to create positive externalities for society.

In addition, proxy variables and what they are controlling for are also important when looking at the effects of social services. Because what we are measuring is directly related to the representative variable we pick. For example, when looking at the impact of education on happiness across countries, one could use the average years of schooling or utilize the proportion of the population with different education levels such as the secondary or high school diploma holder 
percentages. Such an initiative would, in essence, mean comparing the average levels of happiness of the countries associated with the effects of long-term education decisions and investments. ${ }^{17}$

However, in this study, we used the share of government expenditure on education in GDP as a proxy for controlling the education dimension. Therefore, this surrogate variable tends to measure the impact of short-term or recent training investments and thus compare their effects across countries. ${ }^{18}$ Similarly, to control the influence of the health dimension, we use the life expectancy at birth as a proxy variable. As discussed in Section 2, life expectancy is an indicator containing the effects of a series of improvements, which can be considered multidimensional improvements in the long run within a historical perspective, including the public health care provision, increased nutritional possibilities, and better-sheltering potentials, etc. On the other hand, alternatively, it could have also been possible to relate happiness to the short-term effects of the health dimension with an approach such as using the share of health expenditures in GDP.

Our regression results suggest that the higher the carbon dioxide emissions in metric tons per capita are, the lower the average utility level in all models. However, only the estimates in Model 1 and Model 2 are statistically significant. Moreover, the magnitude of the estimated coefficient for this variable is the second-highest in absolute terms, which shows the importance of air pollution and its welfare degrading capability.

Regarding gender equality, it seems that the higher average happiness scores accompany the higher female-to-male ratio in employment in all regressions. One could argue that the approach, which reduces gender issues to a single dimension, such as the contribution of women to production capacity, would be underestimating the depth of the concept. According to Sen (2000), although gender-related factors such as women's economic power, their function outside the family, literacy, education, and property rights may seem distinct, their typical role contributes positively to improving women's voice and agency. In this respect, for example, working outside one's home and having independent income would potentially impact a woman's social standing.

Our regression results do indicate no significant association between trade openness and happiness. One reason for this result would be that increased exports and imports may positively or negatively affect the sectoral employment structure due to a change in product distribution. For example, an increase in exports might often lead to a rise in payments and employment outcomes of the employees who worked in export-oriented industries compared to those employed in other sectors. Therefore, the overall effects of exports on employment-related results depend on the composition of employment across different areas. Similarly, import competition could negatively affect the work opportunities in certain areas by creating a contraction in those sectors. A positive effect on employment is also observable because eliminating existing discriminatory behaviors against certain groups reduces profit margins. Hence, with increasing exports and imports, the overall outcomes in production in different sectors would be determined by the results of those positive and negative effects. In parallel, those positive and negative impacts on employment would also influence the average happiness levels. While those working in industries positively affected by increased trade openness tend to improve the average happiness score, employees in the negatively affected sectors will likely reduce the average happiness level. The competing forces of trade openness could cancel out each other by yielding a result as if there is no effect of trade openness on the average utility.

Our regression for Model 1 reveals a positive association between net international migration and happiness regarding global movements and mobility dimension. Moreover, we also control possible

17 Alternatively, it could be seen as an international comparison of the average satisfaction levels associated with the outcomes of the persons' previously received education.

${ }^{18}$ As an alternative, given that the subjects are the adults in the WVS, it is possible to consider this variable as a control for the public appraise regarding the quality and adequacy of the resources provided for the education of young people. 
non-linearity between two in Model 2; however, the coefficient for the squared time of net migration is found to be insignificant, rejecting the non-linearity. One interpretation for the positive relationship between international net migration and happiness would be that net migration increases the destination country's happiness. On the other hand, another plausible interpretation would be that higher net migration flows more intensively to the destination countries with higher happiness levels. Accordingly, if the data generation for the net migration flows shows an autoregressive process, this could explain the positive sign between net migration and happiness.

To see which one of those interpretations is most likely to be the valid one, we run complementary regressions, which use the proportion of migration stock in population as a proxy variable for the migration rate. Once more, we employ both linear and nonlinear combinations of the percentage of migration stock in population in Model 3 and Model 4, respectively. Model 3 produces an insignificant coefficient estimate for the migration rate variable. When we introduce the squared of the migration rate, both coefficients turn to be significant. Moreover, the estimates reveal a negative sign for the migration stock variable and a positive sign for its square, indicating a U-shaped relationship between the proportion of migration stock in population and happiness. Accordingly, happiness first diminishes with the increases in migrations stock in population, and then it would turn to increase after reaching its minimum. According to our calculations, the turning point occurred as $28.3 \%$ for the percentage of migration stock in population to show a positive relationship between happiness and the migration rate variable. As given in Table 2, the third quartile for the rate of migration stock to population is only $9.87 \%$. For this reason, most of our data is distributed in the low ranges of migration stock. ${ }^{19}$ Hence, for most of our sample, the relationship between migration stock in population and happiness seems negative, implying that average happiness decreases as the migration stock increases.

We can use this finding for our original inquiry to interpret the positive sign for the relationship between net migration and happiness. We can conclude that the positive relationship between net migration and happiness is more likely to exert due to more vigorous net migration movements directed to relatively happier countries.

\section{Conclusion}

This study investigates the development and life satisfaction relationship by handling economic and social progress in a broad sense. The previous studies either have put too much emphasis on the income dimension or used an approach having examined the effect of other aspects separately. Hence, the need for a holistic approach to the topic constitutes the motivation of this research. Our estimations reveal that the income and wealth dimension remains the most important aspect affecting the average happiness level even after controlling other development features. Environment and government effectiveness seem to be different momentous dimensions of development.

Furthermore, social opportunities, including education and health, and gender equality are other influential factors for welfare to a lesser extent. Our econometric models also test the relationship between life satisfaction and international migration. We find a positive correlation between happiness and net migration, implying that net migration movements are primarily directed to relatively happier countries.

An interesting observation for the results is that the magnitude of the regression estimates varies depending on whether selected indicators capture the long-run interactions in a given dimension or not. Accordingly, when a proxy variable captures long-run effects rather than the short-run, the estimated coefficient tends to be relatively low. For example, gender equality- as a component of

19 It seems that the migration stock in the population exceeds the turning point of $28.3 \%$ in only seven countries such as Hong Kong and Kuwait whose population is composed of quite mixed international communities. 
culture- produces a relatively small estimate as opposed to air pollution, whose coefficient is quite significant. Similarly, the share of education expenditure in GDP for education dimension gives a larger estimate than health dimension, controlled by life expectancy at birth. These results are likely sensitive to the proxy variable selection for each dimension because life expectancy contains the long-run developments in the health dimension. At the same time, education expenditures conjecture the relatively short-run advancements in the corresponding aspect. Concerning utility, people tend to respond to the short-run changes more intensively than those for the long run since the latter seems to be exogenous and normalized. Therefore, when measuring the effect of development dimensions on happiness, using different indicators to capture both the long-run and more recent short-run changes in each aspect would prove fruitful insights for future research avenues.

Peer-review: Externally peer-reviewed.

Grant Support: The author received no financial support for the research, authorship, and/or publication of this article.

\section{References}

Bjørnskov, C., Dreher, A., \& Fischer, J. A. (2007). The bigger the better? Evidence of the effect of government size on life satisfaction around the world. Public Choice, 130, 267-292.

Blanchflower, D. G. (2008). International evidence on well-being. IZA Discussion Paper, No. 3354.

Borjas, G. J. (1989). Economic theory and international migration. International Migration Review, 23(3), 457-485.

Box, G. E., \& Cox, D. R. (1964). An analysis of transformations. Journal of the Royal Statistical Society. Series B (Methodological), $262(2), 211-252$.

Carbonell, A. F., \& Gowdy, J. M. (2007). Environmental degradation and happiness. Ecological Economics, 60(3), 509-516.

Clark, A. E., \& Senik, C. (2010). Will GDP growth increase happiness in developing countries? PSE Working Papers no: 2010-43.

Clark, A. E., Frijters, P., \& Shields, M. (2008). Relative income, happiness and utility: An explanation for the easterlin paradox and other puzzles. Journal of Economic Literature, 46, 95-144.

Clark, X., Hatton, T. J., \& Williamson, J. G. (2007). Explaining U.S. immigration, 1971-1998. Review of Economics and Statistics, 89 (2), 359-373.

Coordinated by UNFPA \& IOM. (2013). International migration and development: Contributions and recommendations of the international system. United Nations System Chief Executives Board for Coordination.

Cuñado, J., \& Gracia, F. P. (2013). Environment and happiness: New evidence for Spain. Social Indicators Research, 112(3), 549-567.

Deaton, A. (2008). Income, health and well-being around the world: Evidence from the Gallup World Poll. Journal of Economic Perspectives, 22, 53-72.

Duesenberry, J. S. (1949). Income, savings, and the theory of consumer behavior. Cambridge, MA: Harvard University Press. 
Easterlin, R. (1974). Does economic growth improve the human lot? In P. A. David, \& M. W. Reder (Eds.). Nations and households in economic growth: Essays in honor of moses abramovitz (pp.89125). Palo Alto: Stanford University Press.

Pena, E. A. \& Slate, E.H. (2019). gvlma: Global validation of linear models assumptions. R package version 1.0.0.3. Retrieved from https://CRAN.R-project.org/package=gvlma

Hagerty, M., \& Veenhoven, R. (2003). Wealth and happiness revisited. Social Indicators Research, 64, 1-27.

Headeym, B., \& Wearing, A. (1992). Understanding happiness: A theory of subjective well-being. Melbourne. Melbourne: Longman Cheshire.

Helliwell, J. F., \& Huang, H. (2008). How's your government? International evidence linking good government and well-being. British Journal of Political Science, 38, 595-619.

ILO. (2010). Women in labour markets: Measuring progress and identifying challenges. Geneva: International Labour Organization.

IMF. (2013). IMF discussion note: Women, work, and the economy: macroeconomic gains from gender equity. IMF.

Inglehart, R., C., H., Moreno, A., Welzel, C., K., K., Diez-Medrano, J., . . et al. (2014). World values survey: All rounds - country-pooled datafile 1981-2014. Madrid: JD Systems Institute.

Inglehart, R., Fao, R., Peterson, C., \& C, W. (2008). Development, freedom and rising happiness: A global perspective (1981-2007). Perspectives on Psychological Science, 3, 264-285.

Kaufmann, D., Kraay, A., \& Mastruzzi, M. (2010). The worldwide governance indicators: methodology and analytical issues. World Bank Policy Research Working Paper No. 5430.

Layard, R., Mayraz, G., \& Nickell, S. (2010). Does relative income matter? Are the critics right? In E. Diener, J. Helliwell, \& D. Kahneman, (Eds.) International differences in well-being (pp. 139-165). New York: Oxford University Press.

Massey, D. S. (1988). Economic development and international migration in comparative perspective. Population and Development Review, 14 (3), 383-413.

Massey, D. S., Arango, J., Hugo, G., Kouaouci, A., Pellegrino, A., \& Taylor, J. E. (1993). Theories of international migration: A review and appraisal. Population and Development Review, 19 (3), 431466.

Ott, J. C. (2010). Good governance and happiness in nations: Technical quality precedes democracy and quality beats size. Journal of Happiness Studies, 11 (3), 353-368.

Ott, J. C. (2011). Government and happiness in 130 nations: Good governance fosters higher level and more equality of happiness. Social Indicators Research, 102, 3-22.

Perovic, L. M., \& Golem, S. (2010). Investigating macroeconomic determinants of happiness in transition countries: How important is government expenditure? Eastern European Economics, 48 (4), 59-75.

Polgreen, L. A., \& Simpson, N. B. (2011). Happiness and international migration. Journal of Happiness Studies, 12, 819-840.

$\mathrm{R}$ Core Team (2021). R: A language and environment for statistical computing. R Foundation for Statistical Computing, Vienna, Austria. Retrieved from https://www.R-project.org/.

Ram, R. (2009). Government spending and happiness of the population: Additional evidence from large cross-country samples. Public Choice, 138, 483-490. 
Sen, A. (2000). Development as freedom. New York: Anchor Books.

Sjaastad, L. A. (1962). The costs and returns to human migration. Journal of Political Economy, 70 (5 Part 2), 80-93.

Stevenson, B., \& Wolfers, J. (2008). Economic growth and subjective well-being: Reassessing the easterlin paradox. Brookings Papers on Economic Activity.

Welsch, H. (2002). Preferences over prosperity and pollution: Environmental variation based on happiness surveys. Kyklos, 55 (4), 473-494.

Welsch, H. (2009). Implications of happiness research for environmental economics. Ecological Economics, 68(11), 2735-2742.

Wickham H. (2016). ggplot2: Elegant graphics for data analysis. Springer-Verlag New York.

World Bank. (2011). World development report 2012: Gender equality and development. Washington: World Bank.

Yamamura, E. (2011). The influence of government size on economic growth and life satisfaction. Japanese Economy, 38(4), 28. 